\title{
Inhibition of Glucose-6-Phosphate Dehydrogenase Activity Attenuates Right Ventricle Pressure and Hypertrophy Elicited by VEGFR Inhibitor + Hypoxia
}

\author{
Atsushi Kitagawa, Christina Jacob, Allan Jordan, lan Waddell, Ivan F. McMurtry, \\ and (1) Sachin A. Gupte \\ Department of Pharmacology, New York Medical College, Valhalla, New York (A.K., C.J., S.A.G.); Drug Discovery Unit, Cancer \\ Research UK Manchester Institute, University of Manchester, Macclesfield, United Kingdom (A.J., I.W.); and Departments of \\ Pharmacology and Internal Medicine and Center for Lung Biology, College of Medicine, University of South Alabama, Mobile, \\ Alabama (I.F.M.)
}

Received June 12, 2020; accepted February 16, 2021

\begin{abstract}
Pulmonary hypertension $(\mathrm{PH})$ is a disease of hyperplasia of pulmonary vascular cells. The pentose phosphate pathway (PPP) - a fundamental glucose metabolism pathway-is vital for cell growth. Because treatment of $\mathrm{PH}$ is inadequate, our goal was to determine whether inhibition of glucose-6-phosphate dehydrogenase (G6PD), the rate-limiting enzyme of the PPP, prevents maladaptive gene expression that promotes smooth muscle cell (SMC) growth, reduces pulmonary artery remodeling, and normalizes hemodynamics in experimental models of $\mathrm{PH}$. $\mathrm{PH}$ was induced in mice by exposure to $10 \%$ oxygen $(\mathrm{Hx})$ or weekly injection of vascular endothelial growth factor receptor blocker [Sugen5416 (SU); $20 \mathrm{mg} \mathrm{kg}^{-1}$ ] during exposure to hypoxia $(\mathrm{Hx}+$ $\mathrm{SU})$. A novel G6PD inhibitor $(N-[(3 \beta, 5 \alpha)$-17-oxoandrostan-3-yl] sulfamide; $1.5 \mathrm{mg} \mathrm{kg}^{-1}$ ) was injected daily during exposure to $\mathrm{Hx}$. We measured right ventricle (RV) pressure and left ventricle pressure-volume relationships and gene expression in lungs of normoxic, $\mathrm{Hx}$, and $\mathrm{Hx}+\mathrm{SU}$ and G6PD inhibitor-treated mice. RV systolic and end-diastolic pressures were higher in $\mathrm{Hx}$ and $\mathrm{Hx}+$ $\mathrm{SU}$ than normoxic control mice. $\mathrm{Hx}$ and $\mathrm{Hx}+\mathrm{SU}$ decreased
\end{abstract}

expression of epigenetic modifiers (writers and erasers), increased hypomethylation of the DNA, and induced aberrant gene expression in lungs. G6PD inhibition decreased maladaptive expression of genes and SMC growth, reduced pulmonary vascular remodeling, and decreased right ventricle pressures compared with untreated $\mathrm{PH}$ groups. Pharmacologic inhibition of G6PD activity, by normalizing activity of epigenetic modifiers and DNA methylation, efficaciously reduces $\mathrm{RV}$ pressure overload in $\mathrm{Hx}$ and $\mathrm{Hx}+$ SU mice and preclinical models of $\mathrm{PH}$ and appears to be a safe pharmacotherapeutic strategy.

\section{SIGNIFICANCE STATEMENT}

The results of this study demonstrated that inhibition of a metabolic enzyme efficaciously reduces pulmonary hypertension. For the first time, this study shows that a novel inhibitor of glucose-6-phosphate dehydrogenase, the rate-limiting enzyme in the fundamental pentose phosphate pathway, modulates DNA methylation and alleviates pulmonary artery remodeling and dilates pulmonary artery to reduce pulmonary hypertension.

\section{Introduction}

Pulmonary hypertension $(\mathrm{PH})$ is a multifactorial disease that is defined as sustained elevation of pulmonary arterial pressure (Farber and Loscalzo, 2004). The elevation of pulmonary arterial pressure increases right ventricular (RV) afterload, leading to heart failure and death (Runo

This study was supported by National Institutes of Health National Heart, Blood, and Lung Institute [Grant R01HL132574] (to S.A.G.), American Heart Association Grant-in-Aid [Grant 17GRNT33670454] (to S.A.G.), and Cancer Research UK [Grants C480/A1141 and C5759/A17098] (to A.J. and I.W.).

Some parts of the results were presented at American Heart Association Scientific Session 2019 at Philadelphia, PA

https://doi.org/10.1124/jpet.120.000166. and Loyd, 2003). The main vascular changes in $\mathrm{PH}$ are vasoconstriction, vascular cell proliferation, and thrombosis. Based on these findings, current standard of care is treatment with vasodilators. However, vasodilators such as endothelin receptor blockers, nitric oxide/nitrates, prostacyclin, and phosphodiesterase- 5 inhibitors fail to reverse vascular remodeling, and the long-term prognosis remains poor (Lajoie et al., 2016).

Based on WHO classification, $\mathrm{PH}$ is divided into five groups. WHO group 1 is pulmonary arterial hypertension, group 2 is $\mathrm{PH}$ from left-heart disease, group 3 is $\mathrm{PH}$ from chronic hypoxic lung disease, group 4 is $\mathrm{PH}$ from chronic blood clots, and group 5 is $\mathrm{PH}$ from unclear multifactorial mechanisms (sarcoidosis, hematologic disorders, etc.). The pathogenesis of $\mathrm{PH}$ (group 1

ABBREVIATIONS: Dnmt, DNA methyltransferase; G6PD, glucose-6-phosphate dehydrogenase; Hx, hypoxia; IPA, isolation of small intrapulmonary artery; LVEDP, left ventricle end-diastolic pressure; LVSP, left ventricle end-systolic pressure; mAP, systemic mean arterial pressure; PASMC, pulmonary artery smooth muscle cell; PDD4091, $N$-[(3 $\beta, 5 \alpha)$-17-oxoandrostan-3-yl]sulfamide; PH, pulmonary hypertension; PPP, pentose phosphate pathway; RV, right ventricle; RVEDP, RV end-diastolic pressure; RVSP, RV systolic pressure; SMC, smooth muscle cell; SU, Sugen5416; Tet, ten-eleven translocation. 
and group 2) is still unclear. PH occurs under sustained environmental stress such as inflammation, shear stress, and hypoxia. These stress stimuli contribute to the shifting of pulmonary vascular cells to hyperproliferative and apoptoticresistant phenotypes, allowing abnormal vascular remodeling and PH development (Boucherat et al., 2017; D'Alessandro et al., 2018). Pulmonary vascular cells in patients with $\mathrm{PH}$ also undergo metabolic adaptation to support their high rate of proliferation or inadequate rates of mitotic fission. This metabolic shift, the Warburg phenomenon (Warburg et al., 1927), is a failure of mitochondrial respiration and activation of aerobic glycolysis.

The pentose phosphate pathway (PPP) - a branch of glycolysis and a fundamental glucose metabolism pathway—is vital for cell growth and survival. Glucose-6-phosphate dehydrogenase (G6PD) is the first rate-limiting enzyme of the PPP. G6PD and the PPP generate pentose sugar, which is required for the de novo cellular synthesis of RNA and DNA, and NADPH, a key cofactor for reductive and anabolic reactions. Recently, we found that inhibition and knockdown of G6PD in lungs of a chronic hypoxia-induced $\mathrm{PH}$ mouse model reduced and reversed 1) the Warburg phenomenon, 2) epigenetic modification (DNA methylation), 3) maladaptive expression of genes that support pulmonary artery remodeling, and 4) $\mathrm{PH}$ and left-heart dysfunction (Joshi et al., 2020). However, the role of G6PD in the pathogenesis of hypoxia + Sugen5416-induced PH is unknown. Furthermore, whether inhibition of G6PD reduces remodeling of pulmonary artery and $\mathrm{PH}$ in the hypoxia + Sugen5416 mouse model remains to be determined. We hypothesized that G6PD is a safe pharmacotherapeutic target to reduce $\mathrm{PH}$ in the hypoxia + Sugen5416 mouse model. Therefore, our objectives were to determine whether the inhibition of G6PD activity by pharmacologic manipulations would decrease differential DNA methylation and maladaptive gene expression in lungs and pulmonary vascular cells, reduce vascular remodeling, and normalize hemodynamics in models of chronic hypoxia- and hypoxia + Sugen5416-induced PH (groups 3 and 1, respectively).

\section{Materials and Methods}

Drugs and Reagents. All chemicals and reagents were purchased from Sigma, Thermo Fisher Scientific, and VWR.

Animal Models and Experimental Protocols. All animal experiments were approved by the New York Medical College Animal Care and Use Committee, and all procedures conformed to the guidelines from the NIH Guide for the Care and Use of Laboratory Animals. Male and female C57BL/6J mice (18-32 g) were purchased from the Jackson Laboratory and were randomly divided into four groups: normoxia $(\mathrm{Nx})$, normoxia + Sugen5416 $(\mathrm{Nx}+\mathrm{SU})$, hypoxia $(\mathrm{Hx})$, and hypoxia + Sugen5416 $(\mathrm{Hx}+\mathrm{SU})$ groups. Mice in the $\mathrm{Nx}$ group were placed in a normoxic $\left(21 \% \mathrm{O}_{2}\right)$ environment, and mice in the $\mathrm{Hx}$ group were placed in a normobaric hypoxic chamber $\left(10 \% \mathrm{O}_{2}\right)$ for 6 weeks (Joshi et al., 2020). Mice in the Nx + SU and $\mathrm{Hx}+\mathrm{SU}$ groups received subcutaneous injection of SU5416 $(20 \mathrm{mg} / \mathrm{kg})$ once weekly during 3 weeks of $\mathrm{Nx}\left(21 \% \mathrm{O}_{2}\right)$ or $\mathrm{Hx}\left(10 \% \mathrm{O}_{2}\right)$ as previously described (Vitali et al., 2014). Mice in the drug treatment groups received daily subcutaneous injection of a novel G6PD inhibitor, $N$ [(3 $\beta, 5 \alpha)$-17-oxoandrostan-3-yl] sulfamide (PDD4091; $1.5 \mathrm{mg} \mathrm{kg}$ day $^{-1}$ ) (Hamilton et al., 2012), for 3 weeks. To determine whether PDD4091 reduces $\mathrm{PH}$ in a dose-dependent manner, mice were randomized to receive low-dose $\left(0.15 \mathrm{mg} \mathrm{kg}^{-1} \mathrm{day}^{-1}\right)$, medium-dose $\left(1.5 \mathrm{mg} \mathrm{kg}^{-1}\right.$ day $\left.^{-1}\right)$, or high-dose $\left(15 \mathrm{mg} \mathrm{kg}^{-1}\right.$ day $\left.^{-1}\right)$ injections of PDD4091. $\mathrm{Hx}$ and $\mathrm{Hx}+\mathrm{SU}$ mice are preclinical models of $\mathrm{PH}$ (Stenmark et al., 2009). At the end of the treatment period, hemodynamic measurements were performed, tissue (lungs and arteries) was harvested, and blood samples were collected. Data analysis was performed in a blinded fashion.

Hemodynamic Measurements. All mice were anesthetized with inhalation of isoflurane (isoflurane, USP; 1-chloro-2,2,2-trifluoroethyl difluoromethyl ether; induced at $3 \%$ and maintained at 1.5\%) and placed on a heated table. Closed-chest cardiac catheterization was performed using an MPVS Ultra Single Segment Pressure-Volume Unit (Millar Instruments) in combination with a cardiac catheter. RV systolic pressure (RVSP) and RV end-diastolic pressure (RVEDP) were measured by catheterization of the $R V$ via the right external jugular vein using Millar Mikro-Tip catheter (model SPR-671, tip size of 1.4F; Millar Instruments). The catheter was then removed, and the jugular vein was tied off. For hemodynamic measurements from LV, the right carotid artery was dissected, and a Millar Mikro-Tip conductance catheter (model SPR-839, tip size of 1.4F; Millar Instruments) was introduced into the artery and advanced into the $L V$ via the aortic valve. Once steady-state hemodynamics were achieved, pressure-volume loops were recorded and analyzed using LabChart 8 software (ADInstruments).

Hematocrit Measurements and Blood Chemistry Analysis. After hemodynamic measurements were completed, blood was collected from the cardiac chambers into a heparinized syringe. Heparinized blood was placed in capillary tubes, and hematocrit (\%) was calculated as the length of the erythrocyte layer divided by the length of the entire blood sample. Plasma was shipped to Antech Diagnostics (NC), a GLP facility, where blood tests were performed with routinely used clinical laboratory diagnostic tools.

Assessment of Right Ventricular Hypertrophy. After the cardiac catheterization, the animals were euthanized by cervical dislocation, whole hearts were excised, and RV free wall and LV including ventricular septum $(\mathrm{S})$ were separated and weighed independently. Fulton's index (RV/LV + S ratio) was calculated as an index of RV hypertrophy.

Isolation of Small Intrapulmonary Arteries and IPA Tone Measurements. Mice (25-30 g) were sacrificed by cervical dislocation, and small intrapulmonary arteries (IPA) of third order (100-150 $\mu \mathrm{m}$ in diameter) were isolated from the lung, dissected free of connective tissue, and placed in Krebs' bicarbonate buffer solution (pH 7.4) containing the following (in millimolars): $118 \mathrm{NaCl}, 4.7 \mathrm{KCl}$, $1.5 \mathrm{CaCl}_{2} \times 2 \mathrm{H}_{2} \mathrm{O}, 25 \mathrm{NaHCO}_{3}, 1.1 \mathrm{MgSO}_{4}, 1.2 \mathrm{KH}_{2} \mathrm{PO}_{4}, 5.6$ glucose, and 10 HEPES. Then, the vessels were mounted on a wire myograph (Danish Myo Technology A/S, Aarhus, Denmark) and bathed in Krebs' buffer solution at $37^{\circ} \mathrm{C}$ and an optimal passive tension of $3 \mathrm{mN}$. After 30 minutes of incubation, the arterial viability and equilibration were assessed by the stimulation of the vessels with repeated 10-minute exposures to $\mathrm{KCl}(60 \mathrm{mM}$; $60 \mathrm{~K})$. For registration of vascular ring contractile activity and its following analysis, Chart 5.5.4 and LabChart Reader 8.1.9 (ADInstruments, Inc.) software were used. Vascular tension is presented as a percentage of the maximum steadystate contraction level obtained to the exposure to $60 \mathrm{~K}$.

RNA-seq Analysis. After collecting lungs from $\mathrm{Nx}, \mathrm{Hx}$, and $\mathrm{Hx}+$ SU mice, total RNA was isolated from tissue using the Qiagen All Prep DNA/RNA/miRNA Universal kit according to manufacturer's instructions. RNA was quantified using the NanoDrop (Thermo Fisher Scientific), and quality was assessed using the Agilent Bioanalyzer 2100. RNA-seq library construction was performed using the TruSeq Stranded Total RNA Preparation kit (Illumina) with $200 \mathrm{ng}$ of RNA as input according to the manufacturer's instructions. Libraries were sequenced on the HiSeq2500 with single-end reads of $100 \mathrm{nt}$ at the University of Rochester Genomics Research Center. Single-end sequencing was done at a depth of 10 million reads per replicate. Quantitative analysis, including statistical analysis of differentially expressed genes, was done with Cufflinks 2.0.2 and Cuffdiff2 (http:// cufflinks.cbcb.umd.edu). The Benjamini-Hochberg method was applied for multiple test correction (FDR $<0.05$ ).

Reduced Representation Bisulfite Sequencing. To determine DNA methylation status in lungs of $\mathrm{Nx}, \mathrm{Hx}, \mathrm{Hx}+\mathrm{SU}$, and $\mathrm{Hx}+4091$ 
A

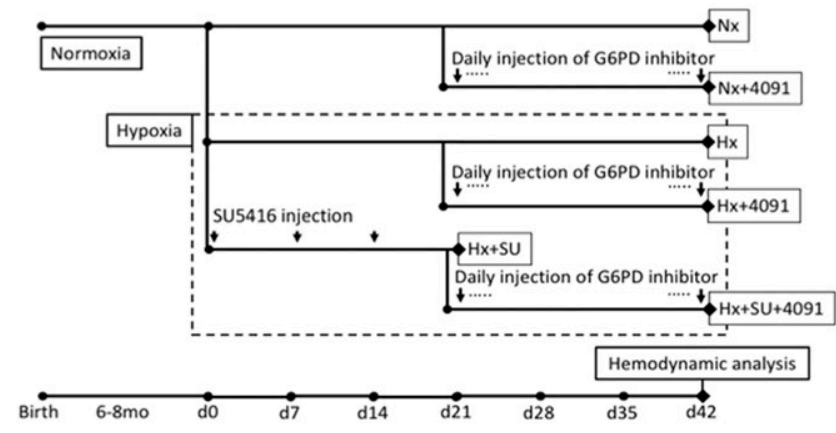

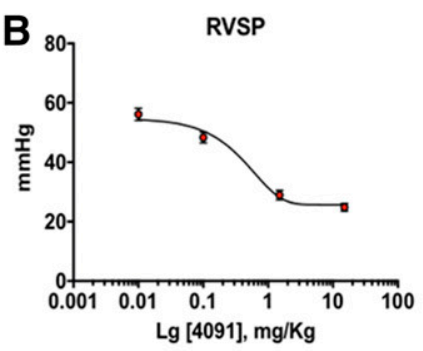

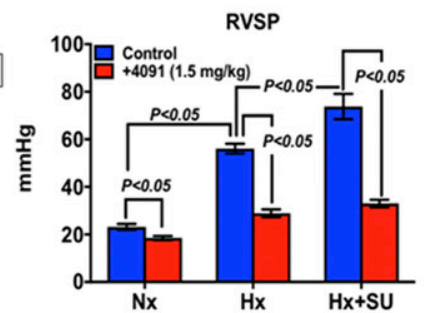

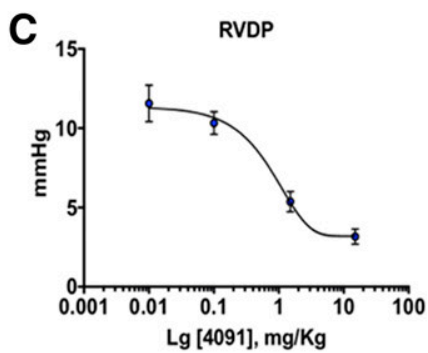

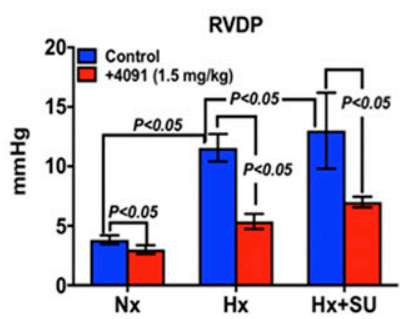

Fig. 1. Daily injection of a novel G6PD inhibitor, PDD4091, decreased pulmonary artery remodeling and right ventricle pressure and hypertrophy in mice elicited by hypoxia and hypoxia + Sugen5416. (A) A schematic showing various treatment protocols in C57BL/6J mice in normoxia and hypoxia and mice treated with Sugen5416 $\left(20 \mathrm{mg} \mathrm{kg}{ }^{-1}\right)$ once a week. (B and C) RVSP and right ventricle diastolic pressure (RVDP) were reduced dose-dependently by PDD4091 treatment of 3 weeks to hypoxic mice. PDD4091 $\left(1.5 \mathrm{mg} \mathrm{kg}^{-1}\right.$ day $\left.{ }^{-1}\right)$ for 3 weeks reduced RVSP and RVDP in mice exposed to hypoxia and hypoxia + Sugen5416. $N=11$, normoxia; $N=6$, normoxia $+4091 ; N=9$, hypoxia; $N=6$, hypoxia $+4091\left(0.10 \mathrm{mg} \mathrm{kg}^{-1} \mathrm{day}^{-1}\right) ; N=11, \mathrm{hypoxia}^{-1} 4091$ $\left(1.5 \mathrm{mg} \mathrm{kg}^{-1} \mathrm{day}^{-1}\right) ; N=6$, hypoxia $+4091\left(15 \mathrm{mg} \mathrm{kg}^{-1} \mathrm{day}^{-1}\right) ; N=5$, hypoxia + Sugen5416 $\left(20 \mathrm{mg} \mathrm{kg}^{-1}\right) ;$ and $N=5$, hypoxia + Sugen5416 (20 mg kg $\left.{ }^{-1}\right)$ $+4091\left(1.5 \mathrm{mg} \mathrm{kg}^{-1} \mathrm{day}^{-1}\right)$. Each group included male and female mice (2:1 ratio). Statistical analysis was performed using two-way ANOVA and Sidak's test for multiple comparisons.

mice, genomic DNA was isolated from lungs using the Qiagen All Prep DNA/RNA/miRNA Universal kit according to the manufacturer's instructions. DNA was quantified using the NanoDrop (Thermo Fisher Scientific) and Qubit Fluorometer (Thermo Fisher Scientific). Genomic DNA quality was assessed using the Agilent TapeStation. Reduced representation bisulfite sequencing library construction was performed with the Premium Reduced Representation Bisulfite Sequencing Kit (Diagenode) following the manufacturer's instructions. Libraries were sequenced on the HiSeq2500 with paired-end reads of $125 \mathrm{nt}$. Raw reads generated from the Illumina HiSeq2500 sequencer were de-multiplexed using bcl2fastq version 2.19.0. Quality filtering and adapter removal are performed using Trim Galore version 0.4.4_dev with the following parameters: "-paired-clip_R1 3-clip_R2 3-three_prime_clip_R1 2-three_prime_clip_R2 2" (http:// www.bioinformatics.babraham.ac.uk/projects/ trim_galore/). Processed and cleaned reads were then mapped to the mouse reference genome (mg38) using Bismark version 0.19.0 with the following parameters: “-bowtie2-maxins 1000." Differential methylation analysis was performed using methylKit version 1.4 .0 within an $R$ version 3.4.1 environment. Bismark alignments were processed via methylKit in the $\mathrm{CpG}$ context with a minimum quality threshold of 10 . Coverage was normalized after filtering for loci with a coverage of at least five reads and no more than the 99.9 th percentile of coverage values. The coverage was then normalized across samples, and the methylation counts were aggregated for 500-nt windows spanning the entire genome. A unified window set across samples was derived such that only windows with coverage by at least one sample per group were retained. Differential methylation analysis between conditional groups was performed using the $\chi^{2}$ test and applying a $q$-value (SLIM) threshold of 0.05 and a methylation difference threshold of $25 \%$.

Quantitative Real-Time PCR. Real-time RT-PCR technique was used to analyze mRNA expression. Briefly, total RNA was extracted from lungs using a Qiagen miRNEasy kit (217004). The input RNA quality and concentration were measured on the Synergy HT Take3 Microplate Reader (BioTek, Winooski, VT), and cDNA was prepared using SuperScript IV VILO Master Mix (11756500; Invitrogen) for mRNA. Quantitative PCR was performed in duplicate using TaqMan Fast Advanced Master Mix (44-445-57) for mRNA using a Mx3000p Real-Time PCR System (Stratagene, Santa Clara,
CA). The primers for the QPCR were purchased from Thermo Fisher Scientific/TaqMan. Results for mRNA expression were normalized to internal control Tuba1a, and relative mRNA expression was determined using the $\Delta \mathrm{Ct}$ method.

Cell Culture. Human pulmonary artery smooth muscle cells (PASMCs; Lonza) were maintained at $37^{\circ} \mathrm{C}$ under $5 \% \mathrm{CO}_{2}$ in smooth muscle basal media (CC-3181; Lonza) supplemented with growth factors (SMGM-2 smooth muscle singlequots kit, CC-4149; Lonza). Once cells reached approximately $70 \%$ confluence, they were subcultured using $0.05 \%$ trypsin-EDTA (25300-054; GIBCO, Thermo Fischer Scientific, Grand Island, NY) into six-well plates at about $3 \times 10^{5}$ cells per well.

Statistical Analysis. Statistical analysis was performed using GraphPad Prism 5 software. Values are presented as means \pm S.E. Statistical comparisons of samples were performed with two-way ANOVA followed by Sidak's post hoc test for multiple comparisons and Student's $t$ test for comparing two groups. Differences with $P<0.05$ between the groups were considered significant.

\section{Results}

G6PD Inhibition Decreased Chronic Hx- and Hx + SU-Induced $\mathbf{P H}$ in Mice. $\mathrm{PH}$ was induced by exposing C57BL/6J mice to $\mathrm{Hx}$ and $\mathrm{Hx}+\mathrm{SU}$ (Fig. 1A). C57BL/6J mice exposed to $\mathrm{Hx}$ and $\mathrm{Hx}+\mathrm{SU}$ had higher RVSP and RVEDP than $\mathrm{Nx}$ mice (Fig. 1B). In the $\mathrm{Nx}+\mathrm{SU}$ group, as compared with the Nx group, RVSP (Nx + SU: $24.6 \pm 0.9$ vs. Nx: $23.2 \pm$ $1.3 ; \mathrm{mm} \mathrm{Hg})$ and RVEDP ( $\mathrm{Nx}+\mathrm{SU}: 4.0 \pm 0.4 \mathrm{vs}$. $\mathrm{Nx}: 3.8 \pm 0.4$; $\mathrm{mm} \mathrm{Hg}$ ) were not different. In the $\mathrm{Hx}+\mathrm{SU}$ group, RVSP and RVEDP were higher than those of the Hx group (Fig. 1B).

To determine whether G6PD inhibition reduces $\mathrm{PH}$, we first established the maximum tolerated dose of G6PD inhibitor (PDD4091). The maximum tolerated dose in $\mathrm{Hx}$ mice was $15 \mathrm{mg} \mathrm{kg}{ }^{-1}$ day $^{-1}$, beyond which PDD4091 depressed LV function. More importantly, treatment with the G6PD inhibitor PDD4091 to Hx mice decreased the elevated RVSP and RVEDP in a dose-dependent manner (Fig. 1, B and C, top panel). 
TABLE 1

RV contractility and hypertrophy in Nx control vs. PH groups

The statistical differences between groups was determined by two-way ANOVA followed by Sidak's post hoc test.

\begin{tabular}{|c|c|c|c|c|c|c|}
\hline & $\mathrm{Nx}(n=11)$ & $\mathrm{Nx}+4091(n=6)$ & $\mathrm{Hx}(n=9)$ & $\mathrm{Hx}+4091(n=11)$ & $\mathrm{Hx}+\mathrm{SU}(n=7)$ & $\mathrm{Hx}+\mathrm{SU}+4091(n=6)$ \\
\hline $\mathrm{RV} \mathrm{dP} / \mathrm{dt} \max (\mathrm{mm} \mathrm{Hg} / \mathrm{s})$ & & & $1664 \pm 391$ & $1343 \pm 289$ & $2706 \pm 703^{*}$ & $1647 \pm 114^{\text {ฯ }}$ \\
\hline $\mathrm{RV}-\mathrm{dP} / \mathrm{dt} \min (\mathrm{mm} \mathrm{Hg} / \mathrm{s})$ & $5266 \pm 1029$ & $5890 \pm 570$ & $4945 \pm 788$ & $4753 \pm 553$ & $4648 \pm 1099$ & $4504 \pm 1302$ \\
\hline Fulton's index, RV/LV + S & $0.225 \pm 0.035$ & $0.249 \pm 0.040$ & $0.385 \pm 0.080^{* * *}$ & $0.202 \pm 0.032^{\S \S \S}$ & $0.388 \pm 0.030^{* * *}$ & $0.291 \pm 0.031^{\text {बा ศ }}$ \\
\hline
\end{tabular}
$\mathrm{SuHx}$

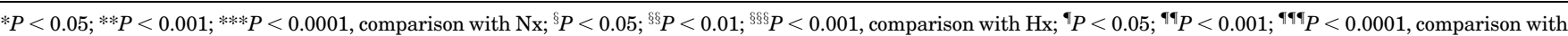

PDD4091 had a reasonably wide therapeutic window $(0.01-15 \mathrm{mg}$ $\mathrm{kg}^{-1}$ day $^{-1}$ ) with an $\mathrm{EC}_{50}$ of $0.26 \pm 0.10$, and $0.58 \pm 0.36 \mathrm{mg} \mathrm{kg}^{-1}$ day $^{-1}$ reduced both RVSP and RVEDP. Moreover, PDD4091 (1.5 mg kg ${ }^{-1}$ day $^{-1}$ ) treatment to both $\mathrm{Hx}$ and $\mathrm{Hx}+\mathrm{SU}$ mice efficaciously reduced the elevated RVSP and RVEDP (Fig. 1, $\mathrm{B}$ and C, bottom panel). Fulton's index was increased in $\mathrm{Hx}$ and $\mathrm{Hx}+\mathrm{SU}$ groups as compared with $\mathrm{Nx}$ and $\mathrm{Nx}+\mathrm{SU}$ groups. G6PD inhibitor reduced elevated Fulton's index in $\mathrm{Hx}$ and $\mathrm{Hx}+\mathrm{SU}$ groups (Table 1). In addition, PDD4091 $\left(1.5 \mathrm{mg} \mathrm{kg}^{-1}\right.$ day $\left.^{-1}\right)$ treatment to mice $(n=6)$ with preexisting $\mathrm{Hx}+\mathrm{SU}-$ induced PH reduced RVSP (from Hx + SU: $74 \pm 5.3$ to Hx + SU + PDD4091: $41 \pm 3.3 \mathrm{~mm} \mathrm{Hg} ; P<0.05)$, RVEDP (from $\mathrm{Hx}+\mathrm{SU}: 13 \pm 3$ to $\mathrm{Hx}+\mathrm{SU}+\mathrm{PDD} 4091: 7 \pm 1 \mathrm{~mm} \mathrm{Hg}$; $P<0.05$ ), and Fulton's index (from $\mathrm{Hx}+\mathrm{SU}: 0.4 \pm 0.01$ to $\mathrm{Hx}+$ SU + PDD4091: $0.3 \pm 0.01 ; P<0.05)$. PDD4091 (1.5 mg kg ${ }^{-1}$ day $^{-1}$ ) reduced G6PD activity by $20 \%$.

$\mathrm{RV} \mathrm{dP} / \mathrm{dt}$ had a tendency to increase in the $\mathrm{Hx}$ group compared with $\mathrm{Nx}$ and significantly increased in $\mathrm{Hx}+\mathrm{SU}$ compared with Nx. PDD4091 treatment $\left(1.5 \mathrm{mg} \mathrm{kg}^{-1}\right.$ day $^{-1}$; Table 1) normalized RV dP/dt in the $\mathrm{Hx}+\mathrm{SU}$ group. LV hemodynamic and function parameters are shown in Table 2. There were no significant differences in mAP, LVSP, LVEDP, and $\mathrm{dP} / \mathrm{dt}$ in the $\mathrm{Hx}$ and $\mathrm{Hx}+\mathrm{SU}$ groups.

Next, we determined the effect of PPD4091 on hematocrit and organ (such as liver, pancreas, and kidney) function. As expected, mice exposed to $\mathrm{Hx}$ had higher hematocrit than $\mathrm{Nx}$ (Table 2). Treating Hx mice with PDD4091 (1.5 mg kg-1 day $^{-1}$ ) for 3 weeks reduced the elevated hematocrit in Hx mice (Table 2). The blood chemistry analysis revealed that PDD4091 treatment normalized electrolyte levels and did not alter organ function in $\mathrm{Hx}$ mice (Table 3).

G6PD Inhibition Relaxed Precontracted PA, Decreased PASMC Growth, and Reduced PA Remodeling in $\mathbf{H x}+\mathbf{S U}$ Mice. PA remodeling is the hallmark of severe PH. Hyperplasic and apoptosis-resistant PA endothelial cells and PASMCs contribute to hypertensive remodeling (Morrell et al., 2009). Previously, we and others proposed that SMCs switch from a differentiated to a dedifferentiated phenotype in PA of hypertensive patients and animals and contribute to PA remodeling (Zhou et al., 2009; Chettimada et al., 2015; Sahoo et al., 2016). Dedifferentiated SMCs are hyperproliferative, migratory, and secretory (Frismantiene et al., 2018). Previous studies show that the $\mathrm{Hx}+\mathrm{SU}$ mouse model of $\mathrm{PH}$ has more severe PA remodeling than $\mathrm{Hx}$ mice (Vitali et al., 2014). Therefore, we determined whether G6PD inhibition relaxes PA in ex vivo studies, stunts the growth of PASMCs exposed to $\mathrm{Hx}$ and $\mathrm{SU}$ in cell culture, and reduces remodeling of $\mathrm{PA}$ in $\mathrm{Hx}$ + SU mice. Our results demonstrated PDD4091 dosedependently relaxed PA precontracted with $\mathrm{KCl}$ (Fig. 2A). Application of PDD4091 [1 $\mu \mathrm{mol} / \mathrm{l}$, an $\mathrm{EC}_{50}$ dose (Hamilton et al., 2012)] for 48 hours to PASMCs cultured in normoxia decreased cell numbers (Fig. 2B) and in addition attenuated the cell growth evoked by $\mathrm{Hx}$ and $\mathrm{Hx}+\mathrm{SU}$ (Fig. 2C). Treatment of $\mathrm{Hx}+\mathrm{SU}$ mice with PDD4091 $\left(1.5 \mathrm{mg} \mathrm{kg}{ }^{-1}\right.$ day $^{-1}$ ) for 3 weeks abrogated the occlusive pulmonary vascular remodeling (Fig. 2D).

Gene Expression Is Altered in Lungs of $\mathrm{Hx}$ and Hx + SU Mice. To discover the genetic and/or epigenetic determinants of PASMC growth in the PA wall and remodeling of PA in $\mathrm{Hx}$ and $\mathrm{Hx}+\mathrm{SU}$, we performed RNA-seq analysis in lungs of mice exposed to $\mathrm{Nx}, \mathrm{Hx}$, and $\mathrm{Hx}+\mathrm{SU}$. Several thousand genes (total 33,141$)$ were upregulated $(15,412)$ or downregulated $(17,729)$ in lungs of mice exposed to $\mathrm{Hx}$ and $\mathrm{Hx}+\mathrm{SU}$ as compared with $\mathrm{Nx}$. The results revealed that out of 159 and 97 genes upregulated $(\geq 1.5 \log 2$ fold; $P<0.05)$ in lungs of $\mathrm{Hx}$ versus $\mathrm{Nx}$ and $\mathrm{Hx}+\mathrm{SU}$ versus $\mathrm{Nx}$ mice, respectively, only three genes were commonly upregulated in both groups (Fig. 3A), whereas out of 1511 and 1523 genes that were downregulated $(\geq 1.5 \log 2$ fold; $P<0.05)$ in lungs of $\mathrm{Hx}$ versus $\mathrm{Nx}$ and $\mathrm{Hx}+\mathrm{SU}$ versus $\mathrm{Nx}$ mice, respectively, 1085 genes were commonly downregulated in both groups (Fig. 3A). Transcription factor binding site enrichment analysis using oPOSSUM (Kwon et al., 2012) disclosed TCFCP211, KLF4, and E2F1 as the most enriched TFBS in

TABLE 2

Systemic blood pressure, LV hemodynamic, and hematocrit changes in Nx control and treatment groups The statistical differences between groups was determined by two-way ANOVA followed by Sidak's post hoc test.

\begin{tabular}{|c|c|c|c|c|c|c|}
\hline & $\mathrm{Nx}(n=11)$ & $\mathrm{Nx}+4091(n=6)$ & $\mathrm{Hx}(n=9)$ & $\mathrm{Hx}+4091(n=11)$ & $\mathrm{SuHx}(n=7)$ & $\mathrm{SuHx}+4091(n=6)$ \\
\hline b.wt. (g) & $23 \pm 3$ & $26 \pm 5$ & $24 \pm 3$ & $23 \pm 3$ & $25 \pm 3$ & $26 \pm 2$ \\
\hline HR (bpm) & $455 \pm 71$ & $508 \pm 71$ & $455 \pm 36$ & $466 \pm 34$ & $519 \pm 19$ & $408 \pm 52^{\text {बा币 }}$ \\
\hline $\mathrm{mAP}(\mathrm{mm} \mathrm{Hg})$ & $87.7 \pm 12.4$ & $76.5 \pm 4.0 *$ & $88.3 \pm 6.7$ & $85.4 \pm 4.8$ & $82.2 \pm 15.3$ & $85.0 \pm 4.0$ \\
\hline LVSP (mm Hg) & $104.0 \pm 11.2$ & $95.5 \pm 3.9$ & $104.8 \pm 5.7$ & $96.8 \pm 3.9$ & $101.8 \pm 21.2$ & $97.9 \pm 4.6$ \\
\hline LVEDP (mm Hg) & $11.2 \pm 2.8$ & $6.2 \pm 3.2$ & $15.2 \pm 3.2$ & $10.7 \pm 1.9$ & $16.5 \pm 9.9$ & $7.9 \pm 2.3$ \\
\hline $\mathrm{dP} / \mathrm{dt} \max (\mathrm{mm} \mathrm{Hg} / \mathrm{s})$ & $5841 \pm 803$ & $6385 \pm 462$ & $5559 \pm 496$ & $5567 \pm 668$ & $6021 \pm 1114$ & $5510 \pm 1302$ \\
\hline$-\mathrm{dP} / \mathrm{dt} \min (\mathrm{mm} \mathrm{Hg} / \mathrm{s})$ & $5266 \pm 1029$ & $5890 \pm 570$ & $4945 \pm 788$ & $4753 \pm 553$ & $4648 \pm 1099$ & $4504 \pm 1302$ \\
\hline $\mathrm{Ht}(\%)$ & $46 \pm 3$ & $44 \pm 2$ & $60 \pm 3^{* * *}$ & $48 \pm 6^{\S \S \S}$ & $59 \pm 3^{* * *}$ & $56 \pm 4$ \\
\hline
\end{tabular}

$\mathrm{HR}$, heart rate; $\mathrm{Ht}$, hematocrit.

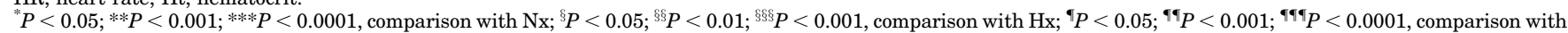
SuHx. 
TABLE 3

Blood chemistry in mice

The statistical differences between groups were determined by two-way ANOVA followed by Sidak's post hoc test.

\begin{tabular}{lccc}
\hline Blood Parameters & $\mathrm{Nx}$ & $\mathrm{Hx}$ & $\mathrm{Hx}+4091$ \\
\hline Blood urea nitrogen (mg/dl) & $31.3 \pm 3.8$ & $31.8 \pm 1.4$ & $36.0 \pm 2.0$ \\
Creatinine (mg/dl) & $0.23 \pm 0.03$ & $0.20 \pm 0.0$ & $0.23 \pm 0.03$ \\
Glucose (mg/dl) & $115 \pm 33$ & $127 \pm 18$ & $145 \pm 19$ \\
$\mathrm{Na}^{+}(\mathrm{mmol} / \mathrm{l})$ & $162 \pm 1$ & $182 \pm 2^{*}$ & $168 \pm 3^{\#}$ \\
$\mathrm{~K}^{+}(\mathrm{mmol} / \mathrm{l})$ & $4.6 \pm 0.4$ & $3.5 \pm 0.1^{*}$ & $4.8 \pm 0.4^{\#}$ \\
$\mathrm{Cl}^{-}(\mathrm{mmol} / \mathrm{l})$ & $125 \pm 1$ & $118 \pm 1^{*}$ & $127 \pm 3^{\#}$ \\
Alkaline phosphatase (U/) & $49 \pm 4$ & $68 \pm 8^{*}$ & $40 \pm 4^{\#}$ \\
Alanine aminotransferase (U/l) & $9 \pm 2$ & $6 \pm 1$ & $5 \pm 2$ \\
Aspartate aminotransferase (U/l) & $75 \pm 6$ & $106 \pm 28$ & $75 \pm 2$ \\
Total bilirubin (mg/dl) & $0.1 \pm 0.0$ & $0.1 \pm 0.0$ & $0.1 \pm 0.0$ \\
Direct bilirubin (mg/dl) & $0 \pm 0 \pm 0$ & $0 \pm 0$ \\
Lactate dehydrogenase (U/l) & $374 \pm 78$ & $0 \pm 0$ & $449 \pm 22$ \\
Creatine kinase (U/) & $254 \pm 57$ & $367 \pm 39$ & $136 \pm 21$ \\
Total protein (g/dl) & $3.6 \pm 0.1$ & $268 \pm 68$ & $3.7 \pm 0.1^{\#}$ \\
Albumin (g/dl) & $2.1 \pm 0.1$ & $3.2 \pm 0.1^{*}$ & $2.1 \pm 0.1^{\#}$ \\
Ca ${ }^{2+}(\mathrm{mg} / \mathrm{dl})$ & $7.6 \pm 0.2$ & $1.1 \pm 0.1^{*}$ & $7.2 \pm \pm .2^{\#}$ \\
PHOS (mg/dl) & $9.2 \pm 1.7$ & $6.6 \pm 0.1^{*}$ & $9.4 \pm 1.2$ \\
Mg (mg/dl) & $2.2 \pm 0.1$ & $8.3 \pm 0.9$ & $2.3 \pm 0.3$ \\
Cholesterol (mg/dl) & $44 \pm 8$ & $2.2 \pm 0.1$ & $66 \pm 7$ \\
Triglycerides (mg/dl) & $46 \pm 13$ & $52 \pm 3$ & $64 \pm 9$ \\
Amylase (U/l) & $406 \pm 64$ & $82 \pm 15$ & $387 \pm 34$ \\
Lipase (U/l) & $87 \pm 20$ & $300 \pm 13$ & $42 \pm 7^{*}$ \\
\hline
\end{tabular}

The statistical differences between groups was determined by two-way ANOVA followed by Sidak's post hoc test. ${ }^{*} P<0.05$ vs. $\mathrm{Nx}$ and ${ }^{\#} P<0.05$ vs. Hx.

genes upregulated in the Hx group and HIF1A::ARNT, KLF4, and SP1 as the most enriched TFBS in genes upregulated in the $\mathrm{Hx}+\mathrm{SU}$ group (Fig. 3B, top panels). HOXA5, PDX1, and PRRX2 were the most enriched TFBS in genes downregulated in the $\mathrm{Hx}$ and $\mathrm{Hx}+\mathrm{SU}$ groups (Fig. 3B, bottom panels). Suppressor of fused (Sufu) homolog and Cyp1a1 genes, respectively, upregulated $>100$ - and $>15$-fold in lungs of mice exposed to $\mathrm{Hx}+\mathrm{SU}$, but not to $\mathrm{Hx}$, and all genes downregulated $>20$-fold were common in lungs of mice exposed to $\mathrm{Hx}+\mathrm{SU}$ and $\mathrm{Hx}$ (Fig. 3C).

G6PD Inhibition Decreased Expression of Cyp1a1 and Sufu Genes in Lungs of Mice and in Human PASMCs Exposed to Hx + SU. Next, we determined whether inhibition of G6PD activity decreases expression of Cyp $1 a 1$ and Sufu, which are increased in lungs of hypertensive mice (Fig. 3C) and $\mathrm{Hx}$ and $\mathrm{Hx}+\mathrm{SU}$ mice and in human PASMCs exposed to $\mathrm{Hx}+\mathrm{SU}$. Treatment of PDD4091 (1.5 mg kg ${ }^{-1}$ day $^{-1}$ ) for 3 weeks to mice and application of PDD4091 $(1 \mu \mathrm{M})$ to human PASMCs for 48 hours rescinded the $\mathrm{Hx}+\mathrm{SU}-$ induced Cyp $1 a 1$ and $\mathrm{Sufu}$

D

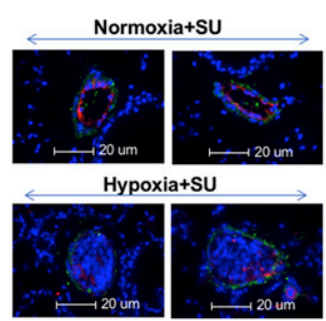

Hypoxia+SU+4091

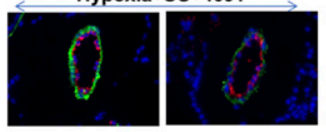

Blue: DAPI; Green: ACTA2; Red: vWF
Fig. 2. G6PD inhibitor, PDD4091, relaxed precontracted PA, decreased PASMC growth, and rescinded occlusive lesion in PA. (A) Application of PDD4091 dosedependently relaxed the pulmonary arterial rings precontracted with $\mathrm{KCl}(30 \mathrm{mM})$; $N=6$ in each dose. (B) Application of PDD4091 (1 $\mu \mathrm{mol} / \mathrm{l})$ to human pulmonary artery smooth muscle cells for 48 hours decreased growth of cells cultured in $21 \% \mathrm{O}_{2}$; $N=6$. (C) Hypoxia $\left(3 \% \mathrm{O}_{2} ; N=6\right)$ and Sugen $(1 \mu \mathrm{mol} / \mathrm{l} ; N=6)$, as compared with normoxia control $\left(21 \% \mathrm{O}_{2} ; N=6\right)$, increased human pulmonary artery smooth muscle cell numbers, and application of PDD4091 ( $1 \mu \mathrm{mol} / \mathrm{l}$; $N=6$ ) to cells for 48 hours reduced their growth. (D) Immunofluorescent micrograph shows occluded pulmonary artery in lungs of mice exposed to hypoxia $+\mathrm{SU}$, and occluded pulmonary arteries were not present in lungs of hypoxia $+\mathrm{SU}$ mice treated with PDD4091 for 3 weeks. $N=4$ in normoxia; hypoxia + SU and hypoxia + $\mathrm{SU}+4091$ groups. ${ }^{*} P<0.05$ vs. $3 \times 10^{-9}$ $\mathrm{M}$ in (A). $* P<0.05$ vs. control or $\mathrm{Nx}$, and ${ }^{\#} P<0.05$ vs. hypoxia in (B and $\mathrm{C}$ ). Statistical analysis was performed by one-way ANOVA in (A and C) and by Student's $t$ test in (B). 


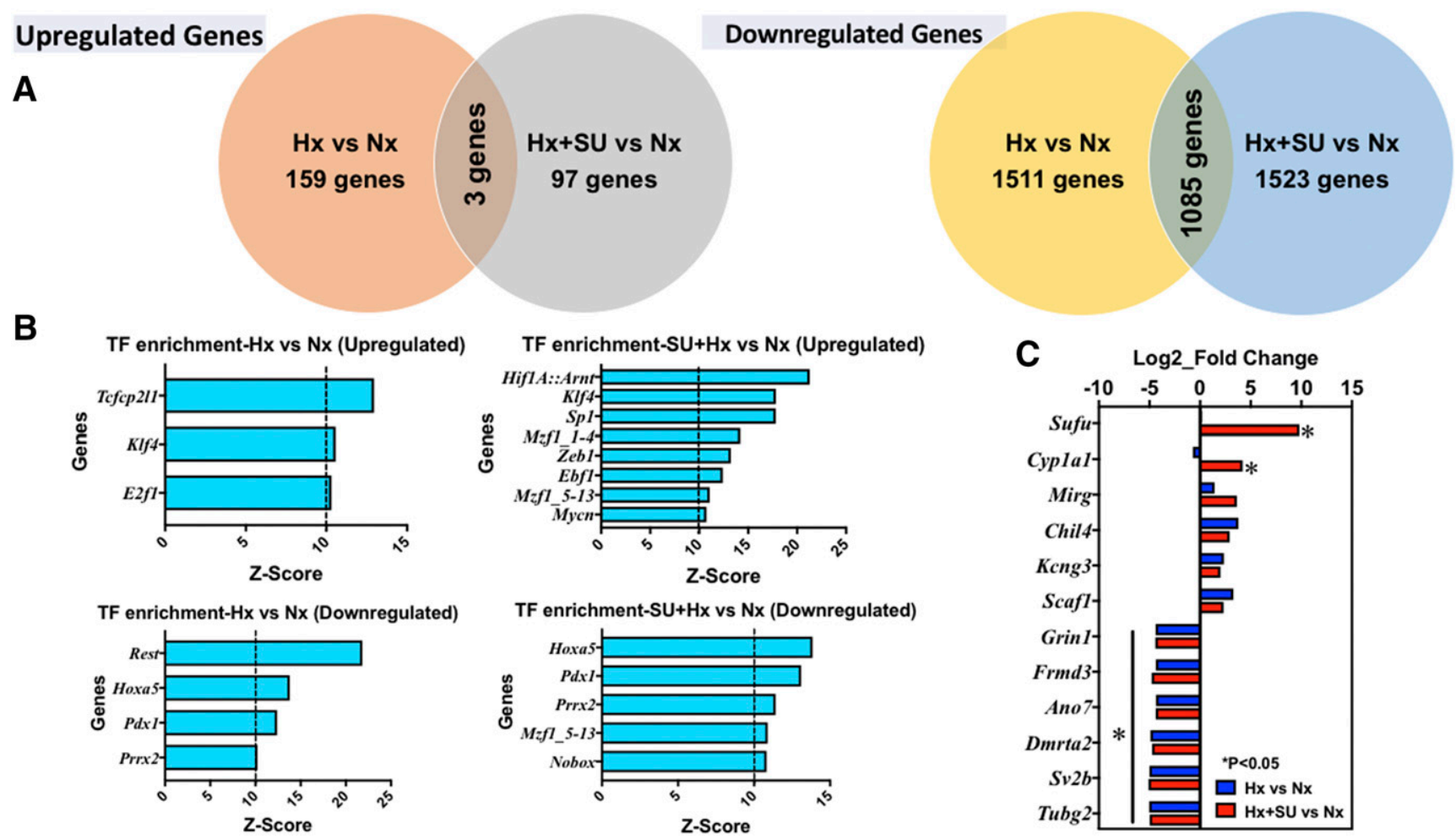

Fig. 3. Gene expression in lungs of mice exposed to hypoxia and hypoxia + Sugen5416. (A) Venn diagram of whole-genome RNA-seq analysis demonstrates that three genes are common in the significantly upregulated cohort and that 1085 genes are common in the significantly downregulated cohort in lungs of mice exposed to $\mathrm{Hx}$ and $\mathrm{Hx}+\mathrm{SU}$ compared with normoxia control (Nx). (B) Transcription factor binding site enrichment analysis using oPPOSUM revealed that TCFCP2L1 and KLF4 in Hx vs. Nx and HIF1A::ARNT and KLF4 in Hx + SU vs. Nx are the most enriched TFBS in the upregulated genes category, and REST and HOXA5 in Hx vs. Nx and HOXA5 and PDX1 in Hx + SU vs. Nx are the most enriched TFBS in the downregulated genes category in mouse lungs. (C) RNA-seq results demonstrate Sufu and Cyp1a1 genes are the most upregulated in lungs of mice exposed to Hx + SU vs. Nx but not to Hx vs. Nx, and Tubg2 and Sv2b genes are the most downregulated in lungs of mice exposed to Hx + SU vs. Nx and to Hx vs. Nx. RNA-seq was performed on three lungs in each group. Male $=2$ and female $=1$. For statistical analysis, the Benjamini-Hochberg method was applied for multiple test correction $(\mathrm{FDR}<0.05)$.

expression in lungs (Fig. 4, A and B) and in human PASMCs (Fig. 4C).

Methylation of DNA Is Decreased in Lungs of Hx and Hx + SU Mice. Epigenetic modifications are incriminated in the pathogenesis of PH (Cheng et al., 2019). Recently, we reported that downregulation of ten-eleven translocation 2 (Tet2) DNA demethylase in lungs of Hx Sv129J mice lacking the Cyp2c44 gene contributes to the genesis of $\mathrm{PH}$ and also demonstrated that inhibition of G6PD was ineffective in reducing $\mathrm{PH}$ in hypoxic Tet2 $2^{-1-}$ mice (Joshi et al., 2020). Therefore, we assumed that downregulation of Tet 2 by $\mathrm{Hx}$ may augment DNA methylation in C57BL/6J mice and mediate maladaptive gene expression. Unexpectedly, we found that expression of Tet1, but not of Tet 2 or Tet 3 , was reduced in lungs of C57BL/6J mice exposed to $\mathrm{Hx}$ (Fig. 5A; Table 4). In addition, expression of Dnmt3b, but not of Dnmt3a
A

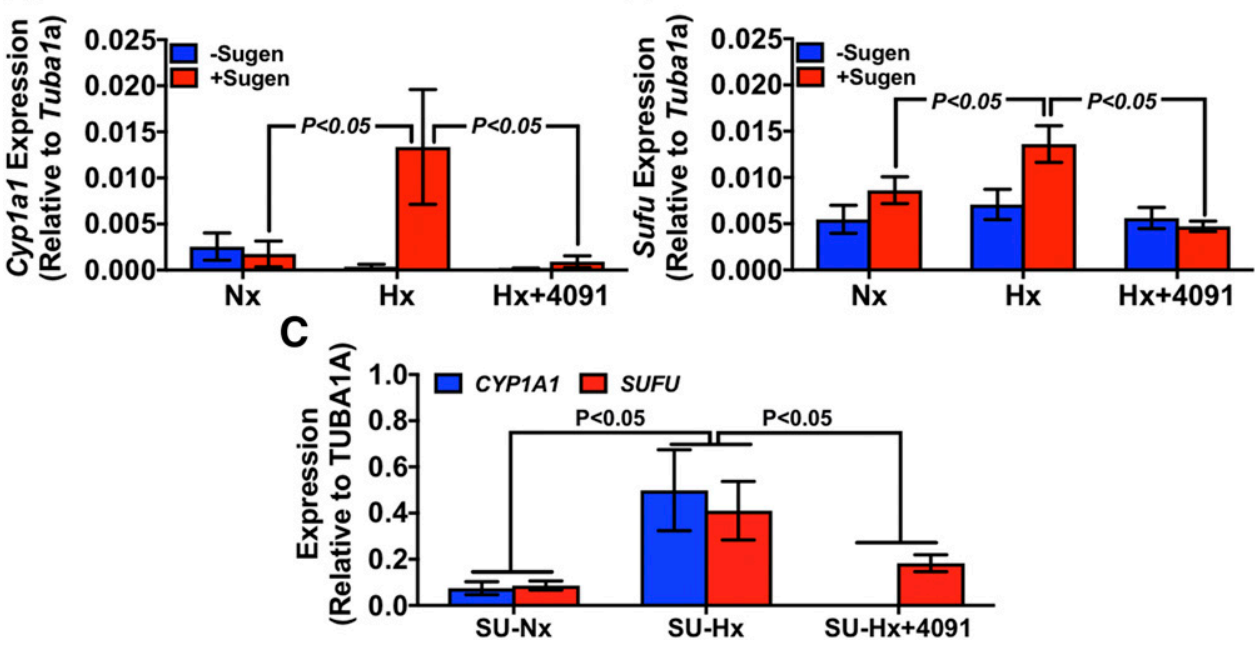

Fig. 4. Expression of $C y p 1 a 1$ and $S u f u$ genes is decreased by the G6PD inhibitor PDD4091. (A and B) Real-time PCR results confirmed RNA-seq results that Cyp1a1 and Sufu are increased in lungs of mice exposed to $\mathrm{Hx}+\mathrm{SU}$ but not to $\mathrm{Hx}$ and that PDD4091 treatment decreased Cyp $1 a 1$ and Sufu. $N=5$ (male $=3$, and female $=2$ ) were used for qPCR analysis in each group. (C) Expression of CYP1A1 and $S U F U$ increased in human pulmonary artery smooth muscle cells cultured in hypoxia $\left(3 \% \mathrm{O}_{2}\right)$, but not in normoxia $\left(21 \% \mathrm{O}_{2}\right)$, by Sugen5416 $(1 \mu \mathrm{mol} / \mathrm{l})$. Application of PDD4091 $(1 \mu \mathrm{mol} / \mathrm{l})$ to cells for 48 hours rescinded their elevated expression of CYP1A1 and SUFU. $N=6$ in each experimental condition. Statistical analysis was performed using two-way ANOVA and Sidak's test for multiple comparisons. 

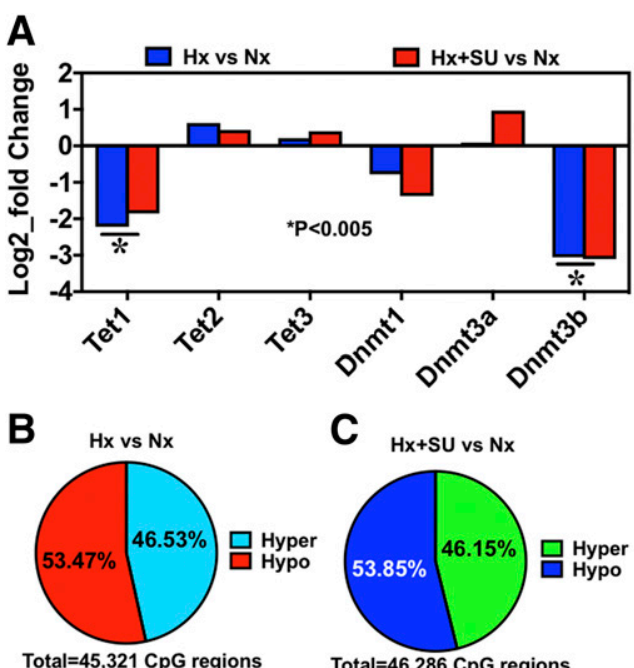

Total $=45,321 \mathrm{CpG}$ regions

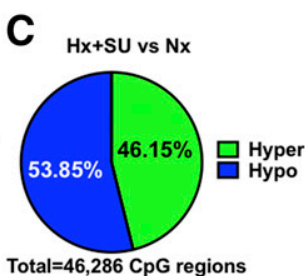

D

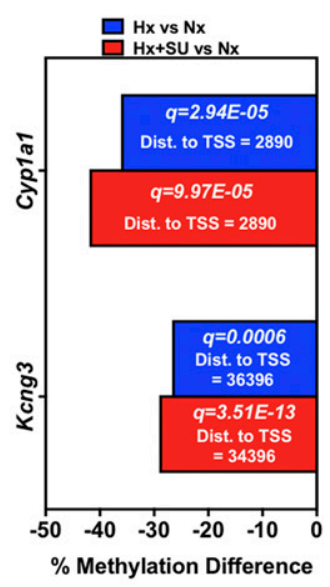

Fig. 5. DNA methylation in lungs of mice exposed to hypoxia and hypoxia + Sugen5416. (A) RNA-seq results disclosed that expression of Tet1 and Dnmt3b genes is significantly decreased in lungs of mice exposed to $\mathrm{Hx}$ and $\mathrm{Hx}+\mathrm{SU}$ as compared with $\mathrm{Nx} . N=3$ in each group. Methylation of the DNA in lungs of mice exposed to $\mathrm{Nx}, \mathrm{Hx}$, and $\mathrm{Hx}+\mathrm{SU}$ was determined by reduced representation bisulfite sequencing method. (B and $\mathrm{C}$ ) The pie graph demonstrates that more $\mathrm{CpG}$ regions are hypomethylated in lungs of $\mathrm{Hx}$ vs. Nx and $\mathrm{Hx}+\mathrm{SU}$ vs. Nx mice. (D) Cyp1a1 and Kcng3 genes are hypomethylated in lungs of $\mathrm{Hx}$ and $\mathrm{Hx}$ + SU mice. The statistical differences in differential methylation between conditional groups was performed using the $\chi^{2}$ test and applying a $q$-value (SLIM) threshold of 0.05 and a methylation difference threshold of $25 \%$. or Dnmt1a, was decreased (Fig. 5A; Table 4). Concomitantly, in lungs of mice exposed to $\mathrm{Hx}$ as compared with $\mathrm{Nx}$ (Fig. 5B), we found that $45,321 \mathrm{CpG}$ regions were differentially methylated, out of which $46.53 \%$ regions were hypermethylated and $53.47 \%$ were hypomethylated, whereas in lungs of mice exposed to $\mathrm{Hx}+\mathrm{SU}$ as compared with $\mathrm{Nx}$ (Fig. 5C), 46,286 $\mathrm{CpG}$ regions were differentially methylated, out of which $46.15 \%$ regions were hypermethylated and $53.85 \%$ were hypomethylated. Therefore, there were $0.38 \%$ more hypomethylated and less hypermethylated $\mathrm{CpG}$ regions in lungs of $\mathrm{Hx}+$ $\mathrm{SU}$ versus $\mathrm{Nx}$ than $\mathrm{Hx}$ versus $\mathrm{Nx}$ C57BL/6J mice. Furthermore, two genes, Cyp1a1 and Kcng3, out of 12 upregulated genes (Fig. 3C), were hypomethylated in lungs of both $\mathrm{Hx}$ versus $\mathrm{Nx}$ and $\mathrm{Hx}+\mathrm{SU}$ versus $\mathrm{Nx}$ C57BL/6J mice (Fig. 5D). It is noteworthy that $\mathrm{CpG}$ regions $2890 \mathrm{bp}$ from the transcription start site of Cyp1a1 gene were hypomethylated in both $\mathrm{Hx}$ versus $\mathrm{Nx}$ and $\mathrm{Hx}+\mathrm{SU}$ versus $\mathrm{Nx}$ groups (Fig. 5D), and G6PD inhibition hypermethylated Cyp1a1 and Kcng3 genes (Table 5).

\section{Discussion}

Pharmacologic inhibition of G6PD activity with the most selective and potent inhibitor synthesized so far/to date, relaxed precontracted PA, decreased growth of PASMCs evoked by $\mathrm{Hx}$ and SU, reduced expression of Cyp1a1 and $S u f u$, and rescinded occlusion of PA in lungs of mice exposed to $\mathrm{Hx}+\mathrm{SU}$. Furthermore, the results of this study provided evidence that downregulation of the epigenetic modifiers Tet1 and Dnmt3b and hypomethylation of DNA altered gene expression in lungs of $\mathrm{Hx}$ and $\mathrm{Hx}+\mathrm{SU}$ mice. Since a selective inhibitor of G6PD activity decreased occlusive remodeling of $\mathrm{PA}$ and alleviated RVSP/heart dysfunction evoked by $\mathrm{Hx}$ and $\mathrm{Hx}+\mathrm{SU}$ in mice, without causing organ toxicity in $\mathrm{Hx}$ mice, we propose that G6PD might be a safe pharmacotherapeutic target to reduce precapillary $\mathrm{PH}$.

$\mathrm{Hx}$ and $\mathrm{Hx}+\mathrm{SU}$ mouse models are routinely used to study the pathology of PH (Stenmark et al., 2009). We observed in this study that mice exposed to $\mathrm{Hx}$ for 6 weeks and to $\mathrm{Hx}+\mathrm{SU}$ for 3 weeks developed $\mathrm{PH}$, which was more severe in the $\mathrm{Hx}+$ SU group than in the $\mathrm{Hx}$ group. In chronically $\mathrm{Hx}$ (3 weeks) mice, vasoconstriction and muscularization of small arteries, but not obliterative remodeling of PA, contribute to increased pulmonary arterial pressure and RV pressure overload (Stenmark et al., 2009). The more severe $\mathrm{PH}$ in $\mathrm{Hx}+\mathrm{SU}$ mice is attributed to the formation of angio-obliterative lesions in addition to vasoconstriction and muscularization (Vitali et al., 2014). Along with vascular pathology, RV pressure and contractility increased in the $\mathrm{Hx}$ and $\mathrm{Hx}+\mathrm{SU}$ groups. Systemic blood pressure (mAP) and LV hemodynamic (LVSP, LVEDP, and dP/dt) was not significantly different in the $\mathrm{Hx}$ and $\mathrm{Hx}+\mathrm{SU}$ groups compared with their control groups. Thus, our results indicate that inhibition of G6PD activity reduces both remodeling of $\mathrm{PA}$ and elevated $\mathrm{RV}$ pressure overload and hypertrophy in two different mouse models of $\mathrm{PH}$.

The above observations raise the question of whether the underlying genetic/epigenetic determinants of $\mathrm{PH}$ in mice exposed to $\mathrm{Hx}$ and $\mathrm{Hx}+\mathrm{SU}$ are the same or different. To seek answers, we performed RNA-seq analysis in lungs, which revealed that $>1000$ downregulated genes and only three upregulated genes, driven by different transcription factors, were common between the two models. Most strikingly, expression of Sufu and Cyp1a1 genes increased $>15$-fold in lungs of mice exposed to $\mathrm{Hx}+\mathrm{SU}$ but not to $\mathrm{Hx}$. Furthermore, exposure to SU increased expression of both $S U F U$ and CYP1A1 genes in $\mathrm{Hx}$ but not in $\mathrm{Nx}$ human PASMCs. Although these results are consistent with a recent study that indicates the HIF::ART-driven Cyp1a1 gene is upregulated in lungs of rats exposed to $\mathrm{SU} / \mathrm{Hx} / \mathrm{Nx}$ and in human PASMCs by $\mathrm{SU}$ (Dean et al., 2018), an increase of $S u$ fu in lungs of $\mathrm{PH}$ mice and human PASMCs has not been reported. CYP1A1 is an

\section{TABLE 4}

Expression of Dnmt and Tet genes in mouse lungs

For statistical analysis, the Benjamini-Hochberg method was applied for multiple test correction $(\mathrm{FDR}<0.05)$

\begin{tabular}{lccccc}
\hline \multirow{2}{*}{ Genes } & \multicolumn{2}{c}{ Hx vs. Nx } & & \multicolumn{2}{c}{$\mathrm{Hx}+$ SU5149 vs. Nx } \\
\cline { 2 - 3 } \cline { 5 - 6 } & Log2_fold & $P$ Value & & Log2_fold & $P$ Value \\
\hline Dmnt1 & -0.775 & 0.1700 & & -1.377 & 0.0158 \\
Dnmt3a & 0.086 & 0.8400 & & 0.969 & 0.0200 \\
Dnmt3b & -3.056 & 0.0028 & & -3.101 & 0.0032 \\
Tet1 & -2.219 & 0.0195 & & -1.852 & 0.0472 \\
Tet2 & 0.628 & 0.2479 & & 0.440 & 0.4165 \\
Tet3 & 0.212 & 0.4949 & & 0.402 & 0.1886 \\
\hline
\end{tabular}


TABLE 5

Methylation status of Cyp1a1 and Kcng3 genes in mouse lungs

The statistical differences in differential methylation between conditional groups was performed using the $\chi^{2}$ test and applying a $q$-value (SLIM) threshold of 0.05 and a methylation difference threshold of 25 percent.

\begin{tabular}{|c|c|c|c|c|c|}
\hline Condition & Gene Name & Strand & Distance from TSS & Differential Methylation & $q$-Value (SLIM) \\
\hline & & & & $\%$ & \\
\hline \multirow[t]{3}{*}{$\mathrm{Hx}$ vs. $\mathrm{Nx}$} & ENSMUST00000034865.4_Cyp1a1 & + & 2890 & -36.1 & $1.42 \mathrm{E}-05$ \\
\hline & & + & 3890 & -25.1 & 0.00366025 \\
\hline & & + & 4390 & -31.4 & $2.25 \mathrm{E}-13$ \\
\hline $\mathrm{Hx}+\mathrm{SU}$ vs. $\mathrm{Nx}$ & ENSMUST00000034865.4_Сyp1a1 & + & 2890 & -41.9 & $3.63 \mathrm{E}-07$ \\
\hline \multirow[t]{3}{*}{$\mathrm{Hx}+4091$ vs. $\mathrm{Hx}$} & ENSMUST00000034865.4_Cyp1a1 & + & 2890 & 36.1 & $7.35 \mathrm{E}-06$ \\
\hline & & + & 3890 & 86.4 & $5.33 \mathrm{E}-31$ \\
\hline & & + & 4390 & 55.0 & $4.27 \mathrm{E}-26$ \\
\hline $\mathrm{Hx}$ vs. Nx & ENSMUST00000051482.1_Kcng3 & - & 36,396 & -26.7 & 0.00044669 \\
\hline $\mathrm{Hx}+\mathrm{SU}$ vs. $\mathrm{Nx}$ & ENSMUST00000051482.1_Kcng3 & - & 34,396 & -29.1 & $3.44 \mathrm{E}-14$ \\
\hline \multirow[t]{2}{*}{$\mathrm{Hx}+4091$ vs. $\mathrm{Hx}$} & ENSMUST00000051482.1_Kcng3 & - & 36,396 & 26.7 & 0.00245735 \\
\hline & & - & 34,396 & -51.7 & $5.03 \mathrm{E}-26$ \\
\hline
\end{tabular}

estrogen-metabolizing enzyme that produces mitogenic metabolites of estrogen in human PASMCs (Dean et al., 2018), and SUFU is a negative regulator of hedgehog signaling, which controls cell proliferation during development in invertebrates and vertebrates ((Briscoe and Thérond, 2013)Briscoe and Therond, 2013; Liu, 2019). Increased CYP1A1 contributes to the pathogenesis of $\mathrm{PH}$ in $\mathrm{SU} / \mathrm{Hx} / \mathrm{Nx}$ rats (Dean et al., 2018). Our results suggest that increased CYP1A1 and SUFU signaling may have a potential role in the genesis of occlusive lesion formation in $\mathrm{Hx}+\mathrm{SU}$ mice. Since transcription of CYP1A1 was abolished and that of SUFU was partially decreased in mouse lungs and in human PASMCs by G6PD inhibition, transcription of CYP1A1 and SUFU genes in lungs and PASMCs exposed to $\mathrm{Hx}+\mathrm{SU}$ is potentially controlled by G6PD. Therefore, we propose that inhibition of G6PD activity could be useful in reversing the elevated expression of the pathogenic $C Y P 1 A 1$ and $S U F U$ genes in $\mathrm{PH}$.

We and others have recently proposed that DNA methylation and other epigenetic modifications potentially promote maladaptive gene expression, a determinant of inflammatory and hyperproliferative cell phenotype, in remodeled PA ( Hu et al., 2019; Joshi et al., 2020; Potus et al., 2020). Furthermore, we recently showed that expression of Tet2, a DNA demethylase considered as a master regulator of differentiated fate of SMC phenotype (Liu et al., 2013), was downregulated in lungs of Sv129J mice with a Cyp2c44 gene knockout (Joshi et al., 2020). Therefore, we assumed that a loss of TET2 modifies DNA methylation and initiates maladaptive gene expression in lungs of mice exposed to $\mathrm{Hx}$ and $\mathrm{Hx}+\mathrm{SU}$. Unexpectedly, expression of Tet1, but not of Tet2, and Dnmt3b was downregulated in lungs of $\mathrm{C} 57 \mathrm{BL} / 6 \mathrm{~J}$ mice exposed to $\mathrm{Hx}$ and $\mathrm{Hx}+$ $\mathrm{SU}$. We propose that genetic variations and differences in gene regulation observed between Sv129J and C57BL/6J mice (Hashimoto et al., 2020) may be a cause of Tet1 and Dnmt3b downregulation, but not of other isoforms of DNA demethylases and methyltransferases, in response to stress observed in C57BL/6J mice. TET proteins are involved in the regulation of hematopoietic stem cell homeostasis and hematologic malignancies and diseases (Nakajima and Kunimoto, 2014). Although loss of a single TET protein is not sufficient to promote malignancies (An et al., 2015), TET1 and TET2 have been shown to, respectively, repress and promote osteogenesis and adipogenesis (Cakouros et al., 2019). Furthermore, inhibition of TET1 blocks expression of large-conductance $\mathrm{Ca}^{2+}$-activated $\mathrm{K}^{+}$channel $\beta 1$ subunit in uterine arteries of pregnant rats (Hu et al., 2017). Expression of this channel is a marker of differentiated SMCs. Therefore, we propose that downregulation of Tet1 could imply that 1) SMCs are dedifferentiated and 2) decreased $\mathrm{Ca}^{2+}$-activated $\mathrm{K}^{+}$channels contribute to constrict PAs and increase pressure in lungs of $\mathrm{Hx}$ and $\mathrm{Hx}+\mathrm{SU}$ mice.

Whereas inhibition of G6PD evoked hypomethylation and increased transcription of the many genes, expression of the Cyp1a1 gene, which promotes PASMC proliferation (Dean et al., 2018), was repressed through hypermethylation of the DNA in lungs of $\mathrm{Hx}$ and $\mathrm{Hx}+\mathrm{SU}$ mice. Therefore, these results suggest that DNA methylation modulated by G6PD is functionally important in gene regulation and substantiate our previous finding that G6PD is a regulator of DNA methyltransferases and demethylase, which plays a crucial role in remodeling of PA (Joshi et al., 2020). In contrast, transcription of Sufu in mouse lungs evoked by $\mathrm{Hx}+\mathrm{SU}$ was not regulated by the methylation of DNA. These results suggest G6PD inhibition activated other mechanisms of gene expression in addition to differential methylation of the DNA and that these mechanisms worked synergistically to regulate gene expression in lungs of $\mathrm{Hx}$ and $\mathrm{Hx}+\mathrm{SU}$ mice.

In addition to arresting maladaptive gene expression in vascular cells of the PA wall and reducing cell growth in occlusive pulmonary arterial disease, PDD4091-a novel and selective inhibitor of G6PD activity (Hamilton et al., 2012)_dose-dependently relaxed precontracted PAs. We have previously shown that inhibition of G6PD activity with nonspecific inhibitors, such as 17-ketosteroids [dehydroepiandrosterone (DHEA) and epiandrosterone, a DHEA metabolite], and siRNA-mediated knockdown of G6pd elicit relaxation of precontracted pulmonary artery (Gupte et al., 2002) and reduce RV pressures in hypertensive rats (Chettimada et al., 2012, 2015). Therefore, these studies and our current findings collectively suggest that G6PD inhibition reduces the elevated $\mathrm{RV}$ pressures and $\mathrm{PH}$ in $\mathrm{Hx}$ and $\mathrm{Hx}+\mathrm{SU}$ mice by dilating PAs and reducing PA remodeling.

In conclusion, our results collectively demonstrate that G6PD activity is an important contributor to differential DNA methylation, maladaptive gene expression, and remodeling of PA in $\mathrm{Hx}$ and $\mathrm{Hx}+\mathrm{SU}$ mice. The inhibition of G6PD activity by pharmacologic manipulations abrogated pulmonary vascular remodeling and improved the hemodynamics in mouse models of PH. Therefore, G6PD inhibitor $N$-[ $[3 \beta, 5 \alpha)-17$ oxoandrostan-3-yl] sulfamide might be employed in the future as a pharmacotherapeutic agent to treat different forms of $\mathrm{PH}$. 


\section{Authorship Contributions}

Participated in research design: Kitagawa, McMurtry, Gupte.

Conducted experiments: Kitagawa, Jacob.

Contributed new reagents or analytic tools: Jordan, Waddell.

Performed data analysis: Kitagawa, Jacob, Gupte.

Wrote or contributed to the writing of the manuscript: Kitagawa, Jacob, McMurtry, Gupte.

\section{References}

An J, González-Avalos E, Chawla A, Jeong M, López-Moyado IF, Li W, Goodell MA, Chavez L, Ko M, and Rao A (2015) Acute loss of TET function results in aggressive myeloid cancer in mice. Nat Commun 6:10071.

Boucherat O, Vitry G, Trinh I, Paulin R, Provencher S, and Bonnet S (2017) The cancer theory of pulmonary arterial hypertension. Pulm Circ 7:285-299.

Briscoe J and Thérond PP (2013) The mechanisms of Hedgehog signalling and its roles in development and disease. Nat Rev Mol Cell Biol 14:416-429.

Cakouros D, Hemming S, Gronthos K, Liu R, Zannettino A, Shi S, and Gronthos S (2019) Specific functions of TET1 and TET2 in regulating mesenchymal cell lineage determination. Epigenetics Chromatin 12:3.

Cheng X, Wang Y, and Du L (2019) Epigenetic modulation in the initiation and progression of pulmonary hypertension. Hypertension 74:733-739.

Chettimada S, Gupte R, Rawat D, Gebb SA, McMurtry IF, and Gupte SA (2015) Hypoxia-induced glucose-6-phosphate dehydrogenase overexpression and -activation in pulmonary artery smooth muscle cells: implication in pulmonary hypertension. Am J Physiol Lung Cell Mol Physiol 308:L287-L300.

Chettimada S, Rawat DK, Dey N, Kobelja R, Simms Z, Wolin MS, Lincoln TM, and Gupte SA (2012) Glc-6-PD and PKG contribute to hypoxia-induced decrease in smooth muscle cell contractile phenotype proteins in pulmonary artery. Am J Physiol Lung Cell Mol Physiol 303:L64-L74.

D’Alessandro A, El Kasmi KC, Plecitá-Hlavatá L, Ježek P, Li M, Zhang H, Gupte SA, and Stenmark KR (2018) Hallmarks of pulmonary hypertension: mesenchymal and inflammatory cell metabolic reprogramming. Antioxid Redox Signal 28:230-250.

Dean A, Gregorc T, Docherty CK, Harvey KY, Nilsen M, Morrell NW, and MacLean MR (2018) Role of the aryl hydrocarbon receptor in sugen 5416-induced experimental pulmonary hypertension. Am J Respir Cell Mol Biol 58:320-330.

Farber HW and Loscalzo J (2004) Pulmonary arterial hypertension. $N$ Engl J Med 351:1655-1665.

Frismantiene A, Philippova M, Erne P, and Resink TJ (2018) Smooth muscle celldriven vascular diseases and molecular mechanisms of VSMC plasticity. Cell Signal 52:48-64

Gupte SA, Li KX, Okada T, Sato K, and Oka M (2002) Inhibitors of pentose phosphate pathway cause vasodilation: involvement of voltage-gated potassium channels. J Pharmacol Exp Ther 301:299-305.

Hamilton NM, Dawson M, Fairweather EE, Hamilton NS, Hitchin JR, James DI, Jones SD, Jordan AM, Lyons AJ, Small HF, et al. (2012) Novel steroid inhibitors of glucose 6-phosphate dehydrogenase. J Med Chem 55:4431-4445.

Hashimoto R, Lanier GM, Dhagia V, Joshi SR, Jordan A, Waddell I, Tuder R, Stenmark KR, Wolin MS, McMurtry IF, et al. (2020) Pluripotent hematopoietic stem cells augment $\alpha$-adrenergic receptor-mediated contraction of pulmonary artery and contribute to the pathogenesis of pulmonary hypertension. Am J Physiol Lung Cell Mol Physiol 318:L386-L401.
Hu CJ, Zhang H, Laux A, Pullamsetti SS, and Stenmark KR (2019) Mechanisms contributing to persistently activated cell phenotypes in pulmonary hypertension. J Physiol 597:1103-1119.

Hu XQ, Dasgupta C, Chen M, Xiao D, Huang X, Han L, Yang S, Xu Z, and Zhang L (2017) Pregnancy reprograms large-conductance $\mathrm{Ca}^{2+}$-activated $\mathrm{K}^{+}$channel in uterine arteries: roles of ten-eleven translocation methylcytosine dioxygenase 1mediated active demethylation. Hypertension 69:1181-1191.

Joshi SR, Kitagawa A, Jacob C, Hashimoto R, Dhagia V, Ramesh A, Zheng C, Zhang H, Jordan A, Waddell I, et al. (2020) Hypoxic activation of glucose-6-phosphate dehydrogenase controls the expression of genes involved in the pathogenesis of pulmonary hypertension through the regulation of DNA methylation. Am J Physiol Lung Cell Mol Physiol 318:L773-L786.

Kwon AT, Arenillas DJ, Worsley Hunt R, and Wasserman WW (2012) oPOSSUM-3: advanced analysis of regulatory motif over-representation across genes or ChIPSeq datasets. G3 (Bethesda) 2:987-1002.

Lajoie AC, Lauzière G, Lega JC, Lacasse $\mathrm{Y}$, Martin S, Simard S, Bonnet $\mathrm{S}$, and Provencher S (2016) Combination therapy versus monotherapy for pulmonary arterial hypertension: a meta-analysis. Lancet Respir Med 4:291-305.

Liu A (2019) Proteostasis in the Hedgehog signaling pathway. Semin Cell Dev Biol 93:153-163.

Liu R, Jin Y, Tang WH, Qin L, Zhang X, Tellides G, Hwa J, Yu J, and Martin KA (2013) Ten-eleven translocation-2 (TET2) is a master regulator of smooth muscle cell plasticity. Circulation 128:2047-2057.

Morrell NW, Adnot S, Archer SL, Dupuis J, Jones PL, MacLean MR, McMurtry IF, Stenmark KR, Thistlethwaite PA, Weissmann N, et al. (2009) Cellular and molecular basis of pulmonary arterial hypertension. J Am Coll Cardiol 54(1 Suppl): S20-S31.

Nakajima H and Kunimoto H (2014) TET2 as an epigenetic master regulator for normal and malignant hematopoiesis. Cancer Sci 105:1093-1099.

Potus F, Pauciulo MW, Cook EK, Zhu N, Hsieh A, Welch CL, Shen Y, Tian L, Lima P, Mewburn J, et al. (2020) Novel mutations and decreased expression of the epigenetic regulator TET2 in pulmonary arterial hypertension. Circulation 141: 1986-2000.

Runo JR and Loyd JE (2003) Primary pulmonary hypertension. Lancet 361: 1533-1544

Sahoo S, Meijles DN, Al Ghouleh I, Tandon M, Cifuentes-Pagano E, Sembrat J, Rojas M, Goncharova E, and Pagano PJ (2016) MEF2C-MYOCD and Leiomodin1 suppression by miRNA-214 promotes smooth muscle cell phenotype switching in pulmonary arterial hypertension. PLoS One 11:e0153780.

Stenmark KR, Meyrick B, Galie N, Mooi WJ, and McMurtry IF (2009) Animal models of pulmonary arterial hypertension: the hope for etiological discovery and pharmacological cure. Am J Physiol Lung Cell Mol Physiol 297:L1013-L1032.

Vitali SH, Hansmann G, Rose C, Fernandez-Gonzalez A, Scheid A, Mitsialis SA and Kourembanas S (2014) The Sugen 5416/hypoxia mouse model of pulmonary hypertension revisited: long-term follow-up. Pulm Circ 4:619-629.

Warburg O, Wind F, and Negelein E (1927) The metabolism of tumors in the body. $J$ Gen Physiol 8:519-530.

Zhou W, Negash S, Liu J, and Raj JU (2009) Modulation of pulmonary vascular smooth muscle cell phenotype in hypoxia: role of cGMP-dependent protein kinase and myocardin. Am J Physiol Lung Cell Mol Physiol 296:L780-L789.

Address correspondence to: Dr. Sachin A. Gupte, New York Medical College, BSB 546, 15 Dana Road, Valhalla, NY 10595. E-mail: sachin_gupte@ yahoo.com or sgupte@nymc.edu 